\title{
Nesnelerin İnterneti Teknolojisinin Lojistik Faaliyetlerindeki Uygulama Alanları ve Verimliliğe Etkileri
}

\author{
Ümit Yılmaz ${ }^{1 *}$ Özlem Kuvat ${ }^{2}$ \\ 1* Balıkesir Üniversitesi, Bigadiç Meslek Yüksekokulu, Yönetim ve Organizasyon Bölümü, Balıkesir, Türkiye, (ORCID: 0000-0003-4268-8598), \\ umityilmaz@balikesir.edu.tr \\ 2 Balıkesir Üniversitesi, İktisadi ve İdari Bilimler Fakültesi, İşletme Bölümü, Balıkesir, Türkiye (ORCID: 0000-0001-7017-4557), ohasgul@balikesir.edu.tr
}

(İlk Geliş Tarihi 5 Ekim 2021 ve Kabul Tarihi 25 Aralık 2021)

(DOI: $10.31590 /$ ejosat.1004953)

\begin{abstract}
ATIF/REFERENCE: Yılmaz, Ü. \& Kuvat, Ö. (2021). Nesnelerin İnterneti Teknolojisinin Lojistik Faaliyetlerindeki Uygulama Alanları ve Verimliliğe Etkileri. Avrupa Bilim ve Teknoloji Dergisi, (31), 746-754.

Öz

Günümüz modern lojistik sistemleri, karmaşık operasyonlar, yoğun ve hızlı çalışma temposu ve özellikle karmaşık çalışma ortamlarında ağır iş yoğunluğu gibi özelliklere sahiptir. Özellikle Covid-19 pandemisinin ardından yaşanan sınırlılıklar ve sorunlar nedeniyle lojistik sektörü bütün dünyada ele alınması gereken en önemli sektörlerden biri durumuna gelmiştir. Lojistik sistemlerindeki iş yoğunluğunun dengelenmesinde ve verimliliğin sağlanmasında dijital teknolojilerden biri olan nesnelerin interneti teknolojisi büyük yer tutmaktadır. Nesnelerin interneti teknolojisinin entegre edildiği sistemler tarafından sağlanan gerçek zamanlı görünürlük ve veriye dayalı bilgiler, başta lojistik sektörü olmak üzere tüm sektörlerde verimliliğin artmasına, maliyetlerin azalmasına, müşteri memnuniyetinin artmasına, pazar payının artmasına ve enerji sarfiyatının azalmasına olanak sağlamaktadır. Bu çalışmada, lojistik faaliyetlerinde nesnelerin interneti teknolojisinin uygulanması neticesinde elde edilecek kazanımları gözler önüne sermek amaçlanmaktadır. Ayrıca çalışmada nesnelerin interneti uygulamalarının neticesinde elde edilecek verimlilik kazanımları üzerinde durulacaktır. Yapılan araştırmanın sonuçları, işletmelerin temel lojistik faaliyetlerinde nesnelerin interneti teknolojisini kullanmalarının fayda, maliyet ve verimlilik açısından büyük avantajlar sağlamalarına olanak sağlayacağını işaret etmektedir. Bunun yanı sıra bu gibi avantajlara karşın işletmelerin nesnelerin interneti teknolojisinin lojistik faaliyetlerine entegrasyonlarında duydukları kaygıların, bu teknolojiye geçiş sürecini geciktirdiği ve hatta durma noktasına getirdiğine yönelik bulgulara rastlanmıştır.
\end{abstract}

Anahtar Kelimeler: Lojistik, Nesnelerin İnterneti, Gerçek Zamanlı Bilgi, Verimlilik.

\section{Applications of Internet of Things Technology in Logistics Activities and Its Effects on Productivity}

\begin{abstract}
Today's modern logistics systems have features such as complex operations, intense and fast work pace and heavy workload, especially in complex working environments. Due to the limitations and problems experienced especially after the Covid-19 pandemic, the Logistics sector has become one of the most important sectors to be addressed all over the world. Internet of Things technology, which is one of the digital technologies, has a great place in balancing the workload and ensuring efficiency in logistics systems. Real-time visibility and data-based information provided by the systems in which Internet of Things technology is integrated allow to increase efficiency, decrease costs, increase customer satisfaction, increase market share and reduce energy consumption in all sectors, especially in the logistics sector. In this study, it is aimed to reveal the gains to be obtained as a result of the application of the Internet of Things technology in logistics activities. In addition, the study will focus on the productivity gains to be obtained as a result of the Internet of Things applications. The results of the research indicate that using the internet of things technology in the basic logistics activities of the enterprises will enable them to provide great advantages in terms of benefit, cost and productivity. In addition, despite such advantages, there were findings that the concerns of the enterprises in the integration of the internet of things technology into their logistics activities delayed the transition to this technology and even brought it to a standstill.
\end{abstract}

Keywords: Logistics, Internet of Things, Real-time Information, Productivity.

* Sorumlu Yazar: umityilmaz@,balikesir.edu.tr 


\section{Giriş}

Nesnelerin interneti (Iot, internet of things), gerçek zamanlı algılama, veri toplama ve paylaşmayı sağlayan yeni bir dijital dönüşüm dalgası olarak gelişmiştir. Nesnelerin interneti, internet üzerinden iletişim kurabilen milyarlarca cihazı bir araya getiren ve ilgili cihazların fiziksel dünyayı algılayabilmesine, gözlem verilerini gönderip alabilmesine ve bu veriler paralelinde hareket etmesine imkan tanıyan bir teknolojidir (Fizza vd., 2021: 1). Nesnelerin internetinin lojistik, sağlık, ulaşım, üretim ve turizm gibi yaygın uygulamaları, toplumların ve ekonomilerin birçok yönünü çarpıcı biçimde dönüştürmektedir (Delgosha vd., 2021: 1). Gelişmiş nesnelerin interneti çözümleri, internet teknolojilerini kullanarak sensörler, cihazlar ve değer zinciri ortaklarının birbirine bağlanmasını sağlar, farklı kaynaklardan veri toplayıp analiz ederek çok daha fazla şeffaflık yaratır ve veri toplama, uzman sistemler ve makine öğrenmesi sistemleri için firsatlar yaratır (Ruile, 2021: 278).

Haziran 2021'de Statista Çevrimiçi Hizmetler tarafindan yayınlanan rapora göre dünya çapında nesnelerin interneti cihazlarının sayısı 2020 yılında 8,74 milyar olup bu sayının 2030 yılında 23,4 milyarı aşacağı tahmin edilmektedir. Endüstriyel ölçekte bakıldığında nesnelerin interneti cihazları elektrik, gaz, buhar, su temini ve atık yönetimi, perakende ve toptan satış, nakliye ve depolama iş kollarında yoğun olarak kullanılmakta ve 2030 yılında endüstriyel ölçekte kullanılan nesnelerin interneti cihazlarının sayısının 8 milyarı aşacağı tahmin edilmektedir (Statista, 2021).

Birçok sektörde faaliyet gösteren işletmeler, rekabetçi olabilmek ve verimliliklerini artırabilmek amaciyla fonksiyonlarını yerine getirirken nesnelerin interneti gibi teknolojilerden faydalanmaktadır. $\mathrm{Bu}$ sayede dijital dönüşüme adapte olmaktadır ve rakiplerine karşı avantajlı duruma gelmektedirler. Lojistik sektörü de teknolojik olanakların mümkün olan en üst düzeyde kullanılmaya çalışıldığ

Lojistiğin gelişimi, teknolojinin ilerlemesi ile yakından ilişkilidir. Teknolojik gelişme perspektifinden lojistiğin evrimi Tablo 1'de gösterilmiştir. Modern lojistiğin gelişimi, lojistik mekanizasyonu, lojistik otomasyon, lojistik entegrasyon ve lojistik zekâ olmak üzere dört aşamadan oluşmaktadır. Tablodan da görüleceği üzere nesnelerin interneti, lojistik zekâ aşamasının anahtar teknolojilerinin ilk sıralarında yer almaktadır (Song vd., 2021: 4253).
Lojistiğin evrimi aşamasında yaşanan bu değişim, mekanizasyon, otomasyon, entegrasyon ve zekâ olarak adlandırılan dönemler boyunca işletmelerde verimliliğin artışında belirgin bir artışa yol açmıştır. Özellikle zekâ olarak adlandırılan bu dönemde teknoloji kullanımıyla ve dijitalleşme ile birlikte sürdürülebilir verimlilik yaklaşımına yönelik kazanımlar da elde edilmiştir.

Lojistik sistemler, genellikle karmaşık ve dinamik özellikler sunan ve tedarik zinciri performansına odaklanan varlık, hizmet, finans ve bilgi akışlarının yönetimini içerir. Nesnelerin İnterneti gibi teknolojik gelişmeler, lojistik sistemlerinde verinin kullanılabilirliğini ve hacmini artırmıştır. Nesnelerin interneti, nispeten yeni bir konsepttir ve Endüstri 4.0'daki dokuz temel teknolojiden biridir (Jagtap vd., 2021: 176). Nesnelerin interneti teknolojileri, lojistik süreçlerde yer alan ekipmanlar, çalışanlar, malzemeler, işler ve bunun gibiler arasındaki bağlantıyı sağlayan, verilerin kesikli olarak toplanmasına izin veren, sistemin mevcut durumunun çeşitli yönlerini göz önünde bulundurarak senkronize karar vermeye rehberlik eden sistemlerdir (Agostino vd., 2020: 387). Lojistik sektörünün süreçlerini otomatikleştirmek, basitleştirmek ve daha verimli hale getirmek için nesnelerin interneti teknolojilerinin kullanılması gerekmektedir (Sergi vd., 2021: 21).

Nesnelerin interneti teknolojisi, lojistik hizmet sağlayıcılarının müşterilerini nasıl izleyecekleri, nasıl yönlendirecekleri ve müşterilere malları nasıl teslim edecekleri konusunda yardımcı olur. Nesnelerin interneti ile donatılmış lojistik faaliyetlerinde, ürünlerin göndericiden alıcıya otonom ve kendi kendini kontrol eden bir şekilde hareket görmesi sayesinde geleneksel lojistik faaliyetlerindeki uzun yanıt süresi birkaç güne indirilir. Bu sayede, lojistik hizmet sağlayıcıları rakiplerine karşı rekabet avantajı elde ederler (Golpîra vd., 2021: 8).

Nesnelerin interneti altyapısı ile donatılmış gerçek zamanlı bilgi işlem teknolojisi, emtia tasarımı, hammadde satın alma, üretim, nakliye, depolama, dağıtım, iadelerin işlenmesi, satış sonrası servis ve yarı ürünler ile nihai ürünlerin satışına kadar tedarik zincirinin hemen hemen her bağlantısının gerçek zamanlı izlenmesine müsaade etmektedir. Bu sayede işletmeler ve hatta tüm tedarik zinciri, karmaşık ve değişken pazarlara en kısa sürede cevap verebilmek için ürünlerle ilgili bilgileri hızlı, zamanında ve doğru bir şekilde elde edebilmektedir (Atzori vd., 2010: 2793 2794).

Tablo 1. Lojistiğin Evrimi (Song vd., 2021: 4253)

\begin{tabular}{|c|c|c|c|c|}
\hline Aşama & Mekanizasyon & Otomasyon & Entegrasyon & Zekâ \\
\hline Özellikler & $\begin{array}{l}\text { Mekanik ekipman insan } \\
\text { gücünün yerini almıştır. }\end{array}$ & $\begin{array}{l}\text { Lojistik işlemleri için ekipman } \\
\text { ve tesislerin otomasyonu } \\
\text { gerçekleştirilmiştir. }\end{array}$ & $\begin{array}{l}\text { Çoklu sistem iş birliği } \\
\text { mevcuttur. }\end{array}$ & $\begin{array}{l}\text { Akıllı işleme, analiz, } \\
\text { karar verme gibi işlevsel } \\
\text { özelliklere sahiptir. }\end{array}$ \\
\hline $\begin{array}{l}\text { Anahtar } \\
\text { Teknolojiler }\end{array}$ & Mekanik imalat & $\begin{array}{l}\text { Sensör, barkod, otomatik } \\
\text { kontrol, bilgisayar teknolojisi }\end{array}$ & $\begin{array}{l}\text { Radyo frekansı ile } \\
\text { tanımlama, İnternet iletişim } \\
\text { teknolojisi }\end{array}$ & $\begin{array}{l}\text { Nesnelerin interneti, } \\
\text { yapay zekâ, büyük veri }\end{array}$ \\
\hline Örnek & Çekici, forklift, vb. & $\begin{array}{l}\text { Otomatik kılavuzlu araçlar, } \\
\text { otomatik depolama ve çekme } \\
\text { sistemi, vb. }\end{array}$ & $\begin{array}{l}\text { Lojistik bilgi yönetim } \\
\text { sistemi, vb. }\end{array}$ & $\begin{array}{ll}\text { İnsansız hava } & \text { araçları, } \\
\text { Otomatik } & \text { teslimat } \\
\text { robotu, vb. } & \end{array}$ \\
\hline
\end{tabular}




\section{Nesnelerin İnterneti Uygulamalarında Kullanılan Teknolojiler}

Lojistik operasyonlarının performansı esas olarak karar vermenin sonuçlarına bağlı olduğundan, nesnelerin interneti, verimli veri toplama, işleme ve analiz yoluyla karar verme süreçlerini iyileştiren veri odaklı teknolojiler olarak önemli bir rol oynamaktadır. Lojistik uygulamalar için temel veri odaklı nesnelerin interneti teknolojileri Tablo 2'de özetlendiği gibi veri toplama, bağlantı ve veri işleme olmak üzere üç ana fonksiyon altında gruplandırılabilir (Tran-Dang vd., 2020: 7).

\subsection{Veri Toplama Teknolojileri}

Veri toplama teknolojileri tanımlama, algılama ve izleme olmak üzere üç grupta değerlendirilebilmektedir.

\subsubsection{Tanimlama Teknolojileri}

Fiziksel nesnenin tanımlanmas1, bir nesnenin belirli bir uygulama alanında uygun bir tanımlayıcı ile benzersiz olarak tanımlanması sürecidir. Nesnenin tanımlanmasının amaçları, nesnelerle ilgili bilgileri almak ve yakalamak ile nesneleri kontrol etmek ve yönetmektir (Hu vd., 2017: 1910). Radyo frekansı ile tanımlama, yakın alan iletişimi, barkod ve karekod gibi teknolojiler, tanımlama alanında yaygın olarak kullanılmaktadır. $\mathrm{Bu}$ sistemlerden en popüleri olan radyo frekansı ile tanımlama sistemleri, işletmelerin gelen siparişleri doğru ve zamanında karşılayabilmeleri için işletmelere tedarik zincirini gerçek zamanlı görme imkanını sağlayabilmektedir. Tedarik zincirinin bu eksiksiz görünürlüğü, şirketlerin süreçlerini minimum maliyetle maksimum verimlilik için sürekli olarak iyileştirmelerine olanak tanıyan olağanüstü bir anlayış sunar. Radyo frekansı ile tanımlamanın kullanılması, malların hareketi ile bilgi talebine dair maliyetlerin minimize edilmesine olanak sağlar. Bunun yanı sıra işletmelere çok zaman kazandırır (Arif vd., 2019: 298).

\subsubsection{Algılama Teknolojileri}

Sıcaklık, darbe ve nem sensörleri gibi akıllı sensörler, ortamdaki ve ürünlerin durumundaki değişiklikleri tespit etmek için kullanılmaktadır. Nesnelerin interneti ile entegre edilen bu veriler, ürünlerin ve ürün ağacında yer alan hammadde ve yardımcı malzemelerin lojistik faaliyetleri süresince sıcaklık, nem ve kalite koşulları değiştirilmeden aktarılmasını sağlamaktadır ve tedarik zinciri paydaşları arasında paylaşılabilmektedir (Anitha vd., 2021: 5). Algilama teknolojileri ile elde edilen veri, nesnelerin interneti teknolojisinin imkanları ile depolanabilmekte ve gerektiği zaman kullanılabilmektedir.

Çok çeşitli akıllı sensörleri birbirine bağlayan heterojen kablosuz sensör ağları, nesnelerin interneti tabanlı sistemlerin temel taşı haline gelmiş ve yakın gelecekte önemli iyileştirmeler sağlamıştır (Gulati vd., 2021: 1). Kablosuz sensör ağlarının teknik gelişimi, akıllı sensörlerden kablosuz akıllı sensörlere bir geçiş yaşamış ve sonunda kablosuz sensör ağlarının üç aşamasına dönüşmüştür. Bunlar; akıllı sensör aşaması, kablosuz akıllı sensör aşaması ve kablosuz iletişim yeteneğidir. Akıllı sensör aşaması, sensör düğümünün çalışma kapasitesini geliştirmek ve genişletmek için sensöre veri hesaplama ve işleme yeteneklerine sahip bir çip yerleştirir. Kablosuz akıllı sensör aşaması, akıllı sensöre dayalı olarak sensör düğümüne kablosuz iletişim teknolojisi ekler. Kablosuz iletişim yeteneği, antenlerin anten farkındalığgını artırır (Ouyang vd., 2019: 2).

Tablo 2. Nesnelerin Interneti Uygulamalarında Kullanılan Teknolojiler (Tran-Dang vd., 2020: 7)

\begin{tabular}{l|l|l}
\hline \multirow{2}{*}{ Fonksiyon } & \multicolumn{2}{l}{ Nesnelerin İnternetine Olanak Sağlayan Teknolojiler } \\
\cline { 2 - 3 } & Sınıflandırma & Örnek Anahtar Teknolojiler \\
\hline \multirow{2}{*}{ Veri toplama } & Tanımlama & Radyo frekansı ile tanımlama, Doğrusal barkod, Karekod, Yakın alan iletişimi \\
\cline { 2 - 3 } & Algılama & Sensörler (Örnek: Biyosensörler, nem, sıcaklık sensörleri) \\
\cline { 2 - 3 } & İzleme & Küresel konumlandırma sistemi, Genel paket radyo servisi \\
\hline \multirow{2}{*}{ Bağlantı } & Küresel kapsama & Hücresel (2G, 3G, 4G, 5G), Uydu \\
\cline { 2 - 3 } & Uzun menzilli kapsama & Düşük güçlü geniş alan (Sigfox, LoRa, NB-IoT, LTE-M) \\
\cline { 2 - 3 } & Kısa menzilli kapsama & Kablosuz bağlantı, Zigbee, Bluetooth, Düşük enerjili bluetooh \\
\hline & \begin{tabular}{l} 
Bulut bilişim: Tüm büyük nesnelerin interneti verileri, uzak ve güçlü bulutta işlenir. \\
\cline { 2 - 3 }
\end{tabular} & $\begin{array}{l}\text { Kenar / Sis bilişim: Nesnelerin interneti veri setleri, performansları iyileştirmek için veri kaynaklarına yakın kenar } \\
\text { nesnelerin interneti cihazlarında veya sis düğümlerinde işlenir. }\end{array}$ \\
\cline { 2 - 3 } & $\begin{array}{l}\text { Büyük veri analitiği, makine öğrenmesi, yapay zekâ: Nesnelerin interneti verilerini analiz etmek ve ardından karar } \\
\text { vermeyi iyileştirmek için eğilimleri tahmin etmek için ilgili algoritmalar kullanılır. }\end{array}$ \\
\cline { 2 - 3 } & $\begin{array}{l}\text { Ara katman: Nesnelerin internetinin özellikleri ne olursa olsun, ara katman yazılımı, zekâ uygulamaları ve hizmetleri } \\
\text { oluşturmak için yalnızca nesnelerin interneti verilerine güvenir. }\end{array}$ \\
\hline
\end{tabular}




\subsection{3. İzleme Teknolojileri}

Çok sayıda nesne, nesnelerin internetine benzersiz bir şekilde tanımlanıp bağlandıkça, nesneler tek tek izlenebilmekte, nesnelerin durumu ve konumu gerçek zamanlı olarak daha üst düzey bir hizmete iletilebilmektedir (Ibarra-Esquer vd., 2017: 14). Teknolojik ilerleme ve nesnelerin interneti sisteminin popülaritesinin bir sonucu olarak GPS (küresel konumlandırma sistemi) ve GPRS (genel paket radyo servisi) gibi teknolojiler, hareket halindeki nesnelerin gerçek zamanlı takibine yönelik gelişmiş ve gerçekçi bir yaklaşım sağlamıştır. $\mathrm{Bu}$ nesnelerin interneti teknolojileri, herhangi bir nesnenin konumunu ve durumunu internet aracılığıyla dinamik olarak verme yeteneğine sahiptir (Thomas ve Rad, 2017: 2). İzleme teknolojinin kullanımıyla elde edilen verilerin eşanlı olarak değerlendirilmesi lojistik hizmet sağlayıcılar tarafından etkili kararların çok hızlı alınmasını sağlamaktadır.

\subsection{Bağlantı Teknolojileri}

Bağlant, bir nesnelerin interneti çözümünün çok önemli bir unsurudur. $\mathrm{Bu}$ nedenle, nesnelerin interneti iletişimlerinin güvenilirliğini garanti etmek ve ortamın kısıtlamalarına uyum sağlamak için aynı nesnelerin interneti uygulamasında birçok protokol kullanılabilir. $\mathrm{Bu}$ kısıtlamalardan bazıları fiziksel kurulum, gerçekleştirilen belirli nesnelerin interneti görevleri ve cihazın bilgi işlem kaynakları ile ilgilidir (Babun vd., 2021: 3). Kablosuz bağlantı, küresel kablosuz ağ, uzun menzilli kablosuz ağ ve kısa menzilli ağ olarak üç ayrı sınıfta incelenebilir.

\subsection{Veri İşleme Teknolojileri}

Veri işleme teknolojilerinden bulut bilişim teknolojisi, neredeyse sınırsız işleme ve depolama kapasitesiyle sağlanmaktadır. Bu teknoloji, nesnelerin interneti teknolojisinin sınırlı depolama ve işleme kapasitesinin teknolojik sınırlamasının üstesinden gelmesine izin verir (Kavre vd., 2019: 2). Böylece, kapasiteye dayalı olan kisitlamalardan kaynaklanan sorunlar da ortadan kalkmaktadır.

Bulut ve nesnelerin interneti arasındaki etkileşimi desteklemeye yönelik artan ihtiyaç, bilgi işlem ve depolama kaynaklarının yalnızca bulutta değil, aynı zamanda veri kaynağına yakın kenarlarda bulunduğu Kenar ve Sis bilişiminine yol açmıştır. Kenar bilişim ve Sis bilişimin bulut nesnelerin internetine entegrasyonu, kritik uygulamalar için gecikmeyi azaltarak ve nesnelerin interneti cihazları tarafindan oluşturulan devasa veri akışını daha iyi yöneterek hem mevcut hem de gelecekteki nesnelerin interneti çözümlerinde büyük sıçrama sağlayacaktır (Firouzi vd., 2021: 2).

Sis bilişimi, tamamen ăg kenarında yer almayan, bulut bilişim bilgi merkezleri arasında ağ oluşturma, depolama ve bilgi işlem kaynakları sağlayan sanallaştırılmış ortamlardır. Sis bilişim, bulut bilişimin bir uzantısıdır ve depolama hizmetlerini kenar cihazlara yaklaştıran cihazlar ile bulut bilişim arasında aracı görevi görür (Sabireen ve Venkataraman, 2021: 164). Nesnelerin interneti teknolojisi, veri toplama fonksiyonunun kullanımıyla elde edilen verinin veri işleme fonksiyonu ile değerlendirilmesi ve analizi lojistik servis sağlayılarının birbirinden farklı çok etkin ve hızlı çözümler sunan dijital dönüşüm aracını kullanmasını sağlayacak ve optimal sonucu veren kararlar almasının yolunu açacaktır.

Nesnelerin interneti uygulamalarının çoğu, tahmin süreçlerinde, veri madenciliğinde ve veri analitiğinde kullanılan akıllı öğrenme mekanizmalarına dayanmaktadır. Makine e-ISSN: 2148-2683 öğrenmesi yaklaşımları ve çözümleme araçları, birçok nesnelerin interneti uygulamasında etkin bir şekilde kullanılmaktadır. Dolayısıyla, makine öğrenmesi ve nesnelerin interneti birbiriyle ilişkili teknolojilerdir. Ayrıca nesnelerin interneti sistemleri, çeşitli modern yapay zekâ yaklaşımlarına bağlıdır. Bu yaklaşımlar, oluşturulan veri ve yönetim gereksinimlerinin devasa boyutuna ek olarak nesnelerin interneti altyapısının karmaşıklığını da dikkate alır (Said ve Tolba, 2021: 1-2).

Veri işleme teknolojilerinden ara katman yazılımı, veritabanları, sunucular, protokoller ve bilgi gönderme ve alma sorguları gibi yazılımlardan oluşur. Nesnelerin internetinin bu yönü, sensörden verileri toplayan, verileri analiz eden ve depolayan bulut ve kablosuz iletişim katmanından oluşur. Ayrıca, ara katman yazılımı istenmeyen bilgileri filtreler ve gerekli verileri göndermek için bulutla iletişim kurar. $\mathrm{Bu}$ bölüm tarafından gerçekleştirilen diğer görevler, heterojen akıllı cihazları bağlamak ve yönetmek, güç tüketimini izlemek ve ayrıca değiş tokuş edilen tüm verilerin gizliliğini ve güvenini güvence altına almaktır (Lawal ve Rafsanjani, 2021: 4).

Bulut, Kenar ve Sis bilişimleriyle birlikte yapay zekâ, veri madenciliği ve makine öğrenmesi gibi bütün bu bileşenler, lojistik sektöründe karşılaşılan karmaşık problemlerin çözümünde hem optimizasyonu sağlamak hem de hız kazanmak adına işletmelere büyük katkıda bulunmaktadır ve buna bağlı olarak verimlilik artışını da sağlamaktadır.

\section{Lojistikte Nesnelerin İnterneti ile Verimli Uygulamalar}

Lojistik alanında nesnelerin internetinin kulanılması farklı fonksiyonların yerine getirilmesi esnasında olabilmektedir. $\mathrm{Bu}$ alanda rekabet avantajı sağlamak için işletmeler dijital dönüşümü ve teknoloji değişimini benimseme yoluna giderek verimliliklerini artırma firsatına sahip olabilmektedir. Özellikle taşımacılık yönetimi, depo yönetimi, elleçleme, paketleme, dağıtım, lojistik bilgi işlem sistemi, talep tahmini gibi alanlarda bu yaklaşımın kullanılması işletmeler için çok etkili avantajlar sunabilmektedir.

\subsection{Taşımacılık Yönetimi}

Nesnelerin interneti teknolojisi, taşımacılık yönetimi alanında hizmet veren lojistikçilere çeşitli veriler sağlamaktadır. $\mathrm{Bu}$ veriler, yöneticilere teslimat zamanını tahmin etmelerini ve bu tahminlere göre planlama yapmalarını sağlamaktadır (Singh ve Roy, 2020: 310). Lojistik işletmelerinde eşanlı verilere dayalı yapılacak planlama faaliyetleri ve düzenlemeler tüm sürece ilişkin performans artışına yol açmaktadır. Nesnelerin interneti teknolojisinin sağladığı imkanlar sayesinde yaşanan darboğazların ve oluşan kısıtlamaların üstesinden gelmek çok daha hızlı olabilmektedir.

Şekil 1'de görüldüğü üzere günümüzde taşıma araçları yalnızca yük taşımakla kalmamakta, konum, motor durumu, çevresel koşullar, araç verileri, sürücü davranışı ve güvenlik gibi büyük miktarda veri üretmektedir. $\mathrm{Bu}$ verileri bulut tabanlı bir veri sistemine yüklemek ve diğer teknolojilere ve nakliye süreçlerine beslemek, rotalamayı, gönderi takibini, kalite uyumluluğunu, filo yönetimini, sürücü performans yönetimini ve güvenliği destekleyebilir. Uçtan uca nesnelerin interneti özellikli bir taşımacılık sisteminde, bilgi ağ boyunca sorunsuz bir şekilde akacak ve bir bilgi değer döngüsü oluşturacaktır (Taliaferro vd., 2019: 3-4). 


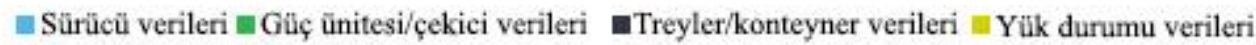

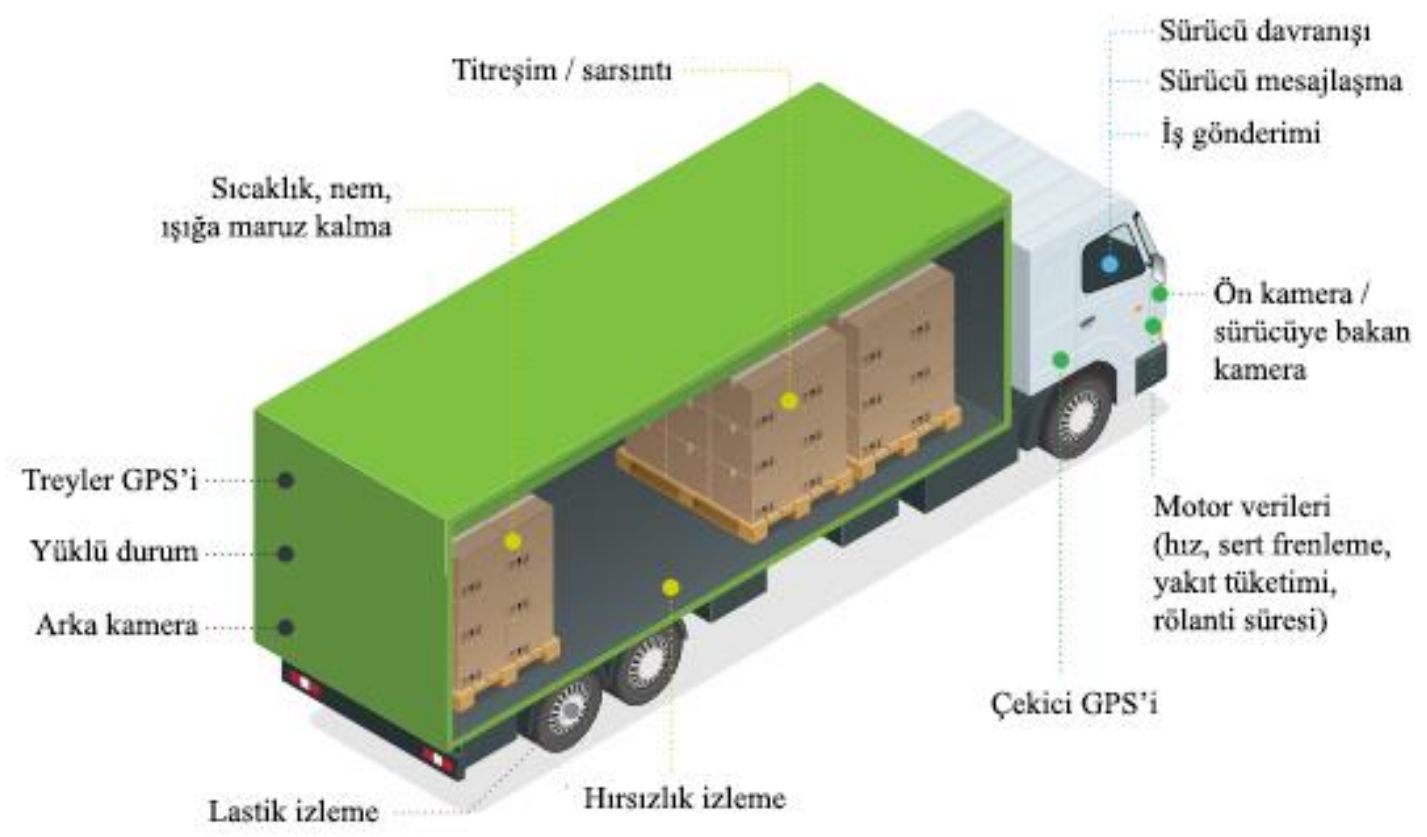

Şekil 1. Nesnelerin İnterneti Tabanlı Taşımacılık Yönetimi

Özetle nesnelerin interneti sayesinde taşımacılık yönetiminde yapılan modernizasyonlar ile araç durumu, yük durumu ve sürücü durumu gerçek zamanlı izleme teknolojisi sayesinde izlenebilmektedir ve bu durumun da çok etkili kazanımları olabilmektedir. Taşımacılık yönetiminde eşanlı takip sayesinde hem herhangi bir plan dışı durumun ortaya çıkmasına ilişkin sorunlar anlık gideribilmekte ve yaşanan tüm değişimlere ilişkin hızlı kararlar alınması sağlanabilmektedir. Ayrıca nesnelerin interneti teknolojisinin sunduğu veri işleme modellerinin ve araçlarının kullanımı taşımacılık sürecinde de verimlilik artışında büyük destek sağlayarak kar optimizasyonuna katkılar sunabilmektedir.

\subsection{Depo Yönetimi}

Nesnelerin interneti, malların depo ağıyla sürekli iletişim halinde olmasını sağlar. Ürünler depodayken, sistem bilgilerin iletimi sayesinde tüm malların her zaman nerede olduğunu bilmelidir (van Geest vd., 2021: 4). Ürünlerin yanı sıra raflar ve operatörler de nesnelerin interneti yardımıyla izlenebilmektedir. $\mathrm{Bu}$ da depo yönetim sisteminde yöneticilere karar desteği sağlamaktadır ve anlık izleme olanağı vermektedir. Depodaki ürün konumlarının görünürlüğünün olmadığı durumlarda, ister insan hatasından isterse diğer faktörlerden kaynaklansın, ürünlerin kaybı ve bilinmeyen depolama yerleri gibi çeşitli sorunlar meydana gelebilmektedir. Ancak, ürünün üretim zamanı, ürünün mevcut konumu ve geçmiş konumları ile bu ürünleri işleyen personelin isimleri ile belirli ayrıntılar bilinirse birçok yaygin problem ortadan kaldırılabilir. Nesnelerin interneti tabanlı gerçek zamanlı bir izleme sistemi, depo görünürlüğünü ve izlenebilirliğini artırmaktadır (G. Zhang vd., 2021: 3). Sistemin sağladığı olanaklar sayesinde eş zamanlı takip ile sadece depo yönetimi için değil üretim sürecinde yaşanan tüm beklemelere ilişkin yeterli bilgi sahibi olması da sağlanmaktadır. Bu sayede üretim verimliliği için de katkı sağlanıp zaman ve malzemeye ilişkin kayıpların da önüne geçilebilmektedir.
Nesnelerin interneti tabanlı gerçek zamanlı izleme teknolojisi eşzamanlı olarak, envanter bilgilerini görsel hale getirmek için toplar ve günceller. $\mathrm{Bu}$ sayede ürün türleri, ürün miktarları, ürünlerin yerleri ve ürünlerin sıcaklık ve nem bazlı depolama koşulları eşzamanlı olarak takip edilebilir. Böylece ürün bilgileri; ürün sinıflandırması, kategorize edilmesi, istiflenmesi ve yönetilmesi için kolaylıkla kullanılabilecektir. Bunun yanı sıra nesnelerin interneti teknolojisinin kullanılması, envanter yönetimi sürecini kolaylaştırmaya, darboğazları gidermeye, depo kaynaklarını verimli bir şekilde tahsis etmeye, depolama verimliliğini artırmaya ve insan hatalarını azaltmaya yardımcı olur (Ding vd., 2021: 330; Zhang vd., 2012: 716). Özellikle bozulmaya karşı hassas veya paketlenme ile ilgili süre konusunda risk taşıyan ürünlerin takibi ve tarihe dayalı önceliklendirilmesi depolarda yaşanan ürün kayıplarının önüne geçme konusunda daha etkili çözümler sunmaktadır.

\subsection{Elleçleme}

Malzeme elleçlemede yoğun bir şekilde faydalanılan personel ve ekipmanlar gibi temel kaynaklar, nesnelerinin interneti teknolojilerinin benimsenmesiyle daha verimli ve ekonomik bir şekilde kullanılabilmektedir. Günümüze kadar çalışanlar tarafından yönetilen lojistik üs yapı, nesnelerin interneti teknolojisi yardımıyla otonom hale gelerek, işletme içerisinde gerçekleştirilen elleçleme faaliyetlerinin çalışan müdahalesi olmadan veya hafif bir çalışan müdahalesiyle hayata geçirilmesine olanak sağlamaktadır. Ayrıca nesnelerin internetinin benimsenmesiyle elleçleme faaliyetinde rastlanılan insan hatalarının önüne geçilmiştir (Buntak vd., 2019: 249; Rey vd., 2021: 585). Nesnelerin interneti teknolojilerinin kullanımı elleçleme faaliyetlerinin planlanması, çizelgelenmesi, modernize edilmesi, izlenmesi, kazaların azaltılması, hızın artırılması gibi pek çok farklı alanda iyileşmeyi beraberinde getirmektedir. 


\subsection{Paketleme}

Nesnelerin interneti gibi ileri teknolojilerin gelişimi ve ambalajın endüstriyel kullanımının artması, ambalajın temel rolleri olan koruma ve iletişim özelliklerinin değişmesini etkilemiştir. Yakın zamanda geliştirilen nano ölçekli malzemeler sayesinde, paketleme fonksiyonu önemli ölçüde iyileştirilirken, iletişim fonksiyonu yüksek performanslı bilgi işlem cihazları tarafindan geliştirilmiştir. $\mathrm{Bu}$ nedenle, geleneksel paketleme yöntemleri nesnelerin interneti teknolojisinin sahip olduğu fonksiyonlar yardımıyla geliştirilen alternatiflerle karşı karşıyadır ve daha gelişmiş paket biçimleri piyasada geliştirilmekte ve mağaza ve tüketici iletişimi için geliştirilmiş bir araç haline gelmektedir (Lydekaityte ve Tambo, 2020: 390). Etiketli paketler, yolculukları sırasında daha fazla görünürlük sağlar. Müşteriler, nesnelerin interneti özellikli çözümlerle paketinin tam konumunu, tahmini varış saatini takip edebilir ve teslimat adresini gerektiği gibi değiştirebilir. Bu durum da teknolojinin sağladığı bir başka avantajdır.

\subsection{Dağıtım}

Birçok lojistik işletmesi, işletmelerin ölçeğinin kademeli olarak genişlemesi ile üretim hacminin değişimi, ürün türlerinin artması ve envanter miktarlarının büyük boyutlara ulaşması nedeniyle dağıtım merkezinde istenilen düzeyde planlama yapamamaktadır. Bundan dolayı alan kullanım oranı düşük olmaktadır ve sorunlar ortaya çıkabilmektedir. Ulaştırma, aktarma ve dağıtım sürecini optimize etmek (şebeke modellerini kullanmak, aktarma ve dağıtım bilgi paylaşımını gerçekleştirmek ve yönetim verimliliğini artırmak) için lojistik sistemlerinin nesnelerin interneti teknolojisiyle modernize edilmesi gerekir $(\mathrm{H}$. Zhang vd., 2021: 175). Dağıtım konusu özellikle lojistik sektörü için büyük önem arzetmektedir. Nesnelerin interneti teknolojisinin kullanımı ve dijital dönüşümdeki gelişmelerin dağıtım alanına yansıtılabilmesi işletmelerin yaşadıkları sorunların büyük ölçüde çözülmesini sağlayacaktır.

\subsection{Lojistik Bilgi İşlem Sistemi}

Lojistik bilgi işlem sistemleri, iş süreçlerinin yeniden düzenlenmesine dayanan, lojistik faaliyetlerin tüm bilgilerini kontrol eden ve entegre eden, dolayısıyla iç ve diş bilgi kaynaklarının paylaşımını ve etkin kullanımını gerçekleştiren ve ilave olarak işletmelerin ekonomik faydalarını ve temel rekabet gücünü artıran teknolojiyi ifade eder (Yu, 2019: 1756). Yani farklı sektörlerdeki bilgi işlem süreçlerine ilişkin bileşenlerin uygulanmasının yanısıra bu sektöre ilişkin özel ihtiyaçların da karşılanabildiği sistemler kullanılabilmektedir.

Geçmişte lojistik bilgi sistemleri genellikle tedarik zincirine zayıf bir şekilde entegre edilmiştir. $\mathrm{Bu}$ durum, uçtan uca görünürlüğü ve gerçek zamanlı karar vermeyi engellemiştir. Ayrıca lojistik sistemlerin kullanımı esas olarak sipariş takibi, araç izleme ve teslimat gibi fonksiyonlarla sınırlı kalmıştır ve daha gelişmiş fonksiyonlar için uygun maliyetli çözümler eksiktir. Neyse ki internet tabanlı bilgi sistemlerine yönelik gelişme, mevcut lojistik bilgi sistemlerinin darboğazlarının çözülmesinde önemli ölçüde katkıda bulunmuştur. Nesnelerin internetinin gelişmiş algılama yetenekleri, ürünlerin tüm lojistik faaliyetlerindeki konumlarını ve durumlarını uzaktan izleme ve kontrol etme olanağı tanımış, buna ilave olarak da uygun maliyetli lojistik çözümlerin geliştirilmesine olanak sağlamıştır (Verdouw vd., 2018: 755). Verinin etkin bir şekilde toplanması ve değerlendirilmesi ile yapılacak planlama çalışmalarında ve optimizasyon modelleme çalışmalarında işletmelerin rekabet e-ISSN: 2148-2683 etmedeki üstünlükleri sağlanabilecek ve verimliliklerinde artış gözlenebilecektir.

\subsection{Talep Tahmini}

Nesnelerin internetinin lojistik faaliyetlerinde uygulanması talebin karşılanmasına yardımcı olmaktadır. Talebin karşılanması lojistik sektöründe verimliliğin en önemli göstergelerinden biridir. Nesnelerin interneti teknolojilerinin sektördeki uygulamaları teknik yönlerle sınırlı değildir; ayrıca talebi tahmin etme yeteneğini geliştiren öngörüler de sağlayabilir. Nesnelerin internetinin entegre edildiği akıllı teknolojiler; kullanıcı davranışı, mevcut pazar eğilimleri, müşteri niyet ve tercihleri, alıcıların satın alma nedenleri ile daha sonra satın aldıkları ürünleri nasıl kullandıkları gibi çok sayıda faktörün kapsamlı bir analizine dayalı olarak talebi tahmin edebilir.

Makine öğrenmesi yaklaşımları ve akıllı öğrenme mekanizmaları kullanarak yapılacak tahminleme çalışmalarında daha düşük hata ile yapılacak tüm tahminler işletmelerin tüm lojistik planlama faaliyetlerinin daha verimli bir şekilde yürütülmesini sağlayacaktır.

\subsection{Optimizasyon}

Lojistik alanında gerçekleşen talepleri karşılamak için geliştirme ve optimize etme ihtiyacı temel bileşenlerden en önemlileridir. Lojistikte daha yüksek otomasyon derecesine dayalı bir optimizasyon, ilgili bilgileri nesnelerin interneti sistemleri aracılığıyla sağlayarak ve paylaşarak, Lojistik 4.0 bağlantılı lojistik ağı düzeyi oluşturarak daha kolay başarılabilmektedir. Yazılım ve veritabanlarına dahil edilmiş akıllı yazılımlar aracılığıyla hem giden lojistiğin hem de gelen lojistiğin optimizasyonu tanımlanabilmektedir. $\mathrm{Bu}$ yazılımlar, internet aracılığıyla daha yüksek bir otomasyon derecesi elde etmek için sistemler hakkında bilgi alışverişi sağlamaktadırlar. Örneğin, küresel konumlandırma sistemi haritalama sistemlerini kurumsal kaynak planlama sistemlerine bağlayarak lojistik çizelgelemeyi geliştirmek mümkün olabilir. Ayrıca bu kullanım, şeffaflığa, gelişmiş karar verici verimliliğine, artan ulaşım kapasitesine, kentsel alanlarda ulaşım optimizasyonuna, otomatik istisna raporlarına, dinamik ürün yönlendirmeye ve ulaşım için çevrimiçi karar desteğine yol açacaktır (Anitha vd., 2021: 1).

Lojistik uygulamalarda öne çıkan bir başka optimizasyon uygulaması örneği depo alanı yapısı optimizasyonudur. Depo alanı optimizasyonu, esas olarak ürün yerleşim planlamasını içerir ve çok etmenli bir mimari çözüm bu alanda kullanılabilir. Uyumluluk kısıtlamaları ile ürün tahsis planlaması, ürünün yerleştirilmesi için bir karar mekanizması kullanan, uyumlulukla ilgili aracılar arasındaki müzakerelere dayalı testler gerçekleştirilebilmektedir. Bu müzakere mekanizması nesnelerin internetine dayanır. Ayrıca otomatik depolama sistemleri de karar alma mekanizmalarına yardımcı uygulamalardır (Song vd., 2021: 4262).

\section{Lojistikte Nesnelerin Interneti Uygulamasının Temel Zorlukları}

Lojistik alanında nesnelerin interneti uygulamasında karşılaşılabilir temel zorluklar; sistem etkinliği ve sürdürülebilirlik, güvenlik; gizlilik, enerji verimliliği ve yatırım maliyeti alanlarında gruplandırılabilir. $\mathrm{Bu}$ alanlarda yaşanabilecek sorunları öncelikle tanımlamak ve sonrasında da sıkıntıların yaşanmasının önüne geçmek amacıyla çeşitli 
araştırmaların yapılması ve etkili önlemlerin alınması gerekmektedir. Bu nedenle işletmelerin dijital teknoloji kullanım deneyimlerinde nesnelerin interneti teknolojisi için de mümkün olduğunca verimli olmak ve üst düzey faydayı sağlamak amacıyla yeterli hazırlıkları yapması gerekmektedir.

\subsection{Sistem Etkinliği ve Sürdürülebilirlik}

Geleneksel olarak internetle ilgili olarak, birlikte çalışabilirlik her zaman temel bir değer olmuştur. Bunun için de birbirine internetle bağlı sistemlerin kodlamalar ve protokoller açısından benzer bir dili konuşma yeteneğine sahip olması gerekir. Şu anda, çeşitli endüstriler uygulamalarını desteklemek için çeşitli standartlar kullanmaktadır. Verilerin büyük miktarları ve türleri ile heterojen aygıtlar sayesinde, bu tür çeşitli varlıklarda standart arayüzlerin kullanılması, çok çeşitli sistem sınırlamalarına ek olarak çapraz organizasyonları destekleyen uygulamalar için de çok önemlidir (Hussein, 2019: 81).

Nesnelerin interneti teknolojisinin bileşenleriyle büyük miktarlardaki verinin işlenmesindeki etkinlik ve hız ayrıca işletmelerin rekabet üstünlüklerinde de fark sağlamaktadır. Bir işletmede sistem etkinliğinin ve sürdürülebilirliğin sağlanmasında dijital teknolojilerin etkisi her zaman yadsınamaz konumdadır. Eğer burada bahsi geçen yapı sağlıklı bir şekilde işletmenin nesnelerin interneti teknolojisinin altyapısında sağlanamadığı taktirde lojistik operasyonların etkinliğinde ve sürdürülebilirliğinde optimalliğe ulaşılamama problemi ortaya çıkacaktır.

\subsection{Güvenlik}

Çeşitli akıllı cihazlardan ve iletim protokollerinden oluşan bir sistemde yer alan birçok düğüm vardır. Nesnelerin interneti ağındaki tek bir düğüm saldırıya uğradığında, nesnelerin interneti sistemi felç olabilir ve bunun sonucunda veri kaybı ve nesnelerin interneti sisteminin belirli fonksiyonlarını yitirmesi gibi problemlerle karşılaşılabilir. Lojistik hizmet sağlayıcıları için bu problemi çözmenin en iyi yollarından biri, nesnelerin interneti ağının güvenilirliğini geliştirmektir (Wang vd., 2021: 13).

Nesnelerin interneti cihazlarının ve uygulamalarının katlanarak artmasıyla orantılı olan nesnelerin interneti ile ilgili güvenlik açıkları hızla büyümektedir. Uygun güvenlik önlemlerinin uygulanmaması, bazı nesnelerin interneti üreticileri ve hizmet sağlayıcıları için itibar ve mali cezalar gibi olumsuz sonuçlar doğurmuştur. Bu nedenle, fiziksel ve sanal altyapılardan oluşan hem küçük hem de büyük ölçekli ağlarda nesnelerin interneti cihazlarını ve uygulamalarını siber saldırılardan korumak için güvenlik çok önemli hale gelmiştir (Tsogbaatar vd., 2021: 2). Dijital teknolojilere ilişkin güvenlik sorunlarının çözümü için geliştirilen yaklaşımlar, lojistik alanında da kullanılabilecek, bu şekilde sorunların mümkün olduğunca ortadan kalması için yine teknolojiden faydalanma söz konusu olabilecektir.

\subsection{Gizlilik}

Her geçen gün artan nesnelerin interneti cihazları ve bu cihazlar tarafından üretilen büyük miktardaki verilerle birlikte gizlilik, nesnelerin interneti ekosisteminde kritik bir endişe haline gelmiştir. $\mathrm{Bu}$ nedenle, cihazında özel bilgi barındıran cihaz sahibinin nesnelerin interneti ekosisteminde herhangi bir sızıntı olmayacağından emin olmak istemektedir. Bir nesnelerin interneti ortamında kişisel verilerin olası sızması veya kötüye kullanılması, önemli gizlilik ihlallerine neden olabilir. Bu nedenle, verilerin yetkisiz kuruluşlara sızdırılmadan veya orijinal amaç dışında kullanılmadan kişisel verilerin hukuka uygun, adil ve şeffaf işlenmesini sağlamak için güvenli mekanizmalar gereklidir (Brotsis vd., 2021: 3). Bu mekanizmaların geliştirilmesi lojistik alanında da hem işletmelerin hem de müşterilerin güvenliklerinden emin olmalarını sağlayacak adımların atılmasına yardımcı olacaktır.

\subsection{Enerji Verimliliği}

Nesnelerin interneti cihazlarının çoğu hareketli olduğundan ve sınırsız bir güç kaynağına bağlı olmadığından, düşük enerji tüketimi nesnelerin interneti teknolojilerini tasarlarken dikkate alınması gereken önemli bir faktördür (Shahid ve Aneja, 2017: 586). Bundan dolayı nesnelerin interneti teknolojisinin temel gereksinimlerinden biri enerji verimliliğidir. Enerji verimli bir ağ, ağın kullanım ömrünün en üst düzeye çıkarılması için minimum enerji tüketimi ile operasyonları yürütme yeteneğine sahip bir ağdır. Bu gereksinim, sınırlı bir ömre sahip ve çoğu zaman değiştirilemeyen pille çalışan cihazlardan oluştuğundan, bir nesnelerin interneti ağında özellikle arzu edilir (Aboubakar vd., 2021: 4). Enerji verimliliğinin sağlanmasıyla minimum enerji tüketimi hem maliyetler açısından hem de yeşil üretimi benimsemiş işletmeler açısından memnun edici sonuçlar ortaya çıkarabilecektir.

\subsection{Yatırım Maliyeti}

Nesnelerin internetini lojistikte başarılı bir şekilde uygulamak, tedarik zincirindeki farklı oyuncular ve rakipler arasında yüksek düzeyde katılımın yanı sıra güçlü bir iş birliği ve ortak bir yatırım isteği gerektirecektir. Nesnelerin internetini de içinde barındıran yeni çözümleri uygulamadan önce tüm ağlarda çeşitli varlık türleri için standartlaşmaya gidilmesi gerekir. Bu da önemli miktarda yatırım yapılması gerektiği anlamına gelmektedir (Macaulay vd., 2015: 25). Bilindiği üzere bir çözüm geliştirilirken maliyet analizi yapılmalıdır. Nesnelerin internetinde bilindiği üzere, nesnelerin interneti cihazlarının, sensörlerinin, ăg geçitlerinin ve baz istasyonu altyapısının çeşitliliği nedeniyle başlangıç maliyetleri çok yüksektir (Akhter ve Sofi, 2021: 14). Bunun yanı sira nesnelerin interneti cihazlarının yönetimi ile veri toplama ve diğer tüm hizmetler arasında bilgi paylaşımı için gerekli olan merkezi hizmetlerin sürdürülebilirliği için ilgili çözümlerin bakım maliyetleri de oldukça yüksektir (Farooq vd., 2019: 156266). Maliyet araştırmaları ve fizibilite çalışmaları sonucunda ölçek ekonomileri ve ödünleşme noktalarının da dikkate alınmasıyla tüm hizmetlere ilişkin farklı maliyet kalemlerinin bir arada değerlendirilmesi gereklidir.

Nesnelerin interneti ürünleri ve çözümleri için uluslararası standartların hala geliştirilme aşamasında olduğu gerçeğine dayanarak, şirketler üçüncü taraf platformları kullanmayı, bünyelerinde bulundurdukları bileşenleri tek tek değiştirmeyi ve hatta altyapıyı tamamen yükseltmeyi gerekli k1lan fonksiyonel uyumsuzluklarla karşı karşıyadır. Nesnelerin interneti sistemini uygulamak isteyen büyük lojistik şirketleri, altyapıyı güncelleme ve nesnelerin interneti teknolojilerinin uygulanmasını yavaşlatan bileşenlerinin uyumluluğunu sağlama ihtiyacıyla karşı karşıyadır (Zaychenko vd., 2021: 194). Herhangi bir yatırım kararı alınmadan önce altyapıya ilişkin çalışmalar da yürütülmeli ve nesnelerin interneti teknolojilerinin kullanmının olurluluğunu da araştırmalıdır. 


\section{Sonuç}

Dijital teknolojiler günümüz koşullarında lojistik sistemlerindeki yaşanan iş yoğunluğunun düzenlenmesinde ve rekabet artışının getirdiği zorluklarla başa çıkmada büyük önem kazanmaktadır. Nesnelerin interneti de bu alanlarda ihtiyaç duyulan düzenlemeyi sağlamak ve verimliliği artırmak için en uygun araçlardan olan dijital teknolojilerden birisi konumundadır.

Lojistik işletmelerinin, faaliyet gösterdikleri pazardaki mevcut konumlarında kalıcı olmak ve hatta yeni pazarlara girebilmek için rekabet güçlerini geliştirmeleri gerekmektedir. Rekabetçi pazar ortamlarına uyum sağlamak amacıyla lojistik işletmelerinin gerçekleştirdikleri faaliyetlerde iyileştirmeye gitmeleri gerekmektedir. Bunun için de lojistik faaliyetlerinin dijitalleştirilmesi gerekir. Dijitalleşme yolunda nesnelerin internetinin entegre olduğu ağlar tarafından oluşturulan ve kaydedilen büyük veriler, lojistik işletmelerinin gerçekleştirdikleri faaliyetler için veriye dayalı çözümler ve geleceğe dönük projeleri için stratejiler oluşturmasına olanak sağlamaktadır.

Bu çalı̧̧mada, lojistik alanında faaliyet gösteren şirketlerin, gerçekleştirdikleri faaliyetlerde nesnelerin interneti teknolojisinin entegrasyonu sonucunda elde edebilecekleri faydalar incelenmiştir. Nesnelerin interneti uygulamalarında kullanılan veri toplama teknolojileri açısından tanımlama, algılama ve izleme amaçlarına yönelik uygulamalar lojistik alanında gereksinimlerin karşılanmasına büyük katkılar sunabilecek fonksiyonlar olacaktır.

Lojistik sektörü dahilinde gerçekleştirilen faaliyetlerde dijital dönüşümün sağlanmasıyla nesnelerin interneti uygulamaları farklı alanlarda değerlendirilebilmektedir. Bu alanlar, taşımacılık yönetimi, depo yönetimi, elleçleme, paketleme, dağıtım, lojistik bilgi işlem sistemi, talep tahmini ve optimizasyon şeklinde gruplandırılabilir ve farklı ihtiyaçlar söz konusu olduğunda nesnelerin interneti teknolojisi olanakları yeniden değerlendirilebilir. Ele alınan bu alanlarda teknolojinin kullanımıyla rekabet avantajının sağlanması ve verimliliğin artırılması mümkün olabilecektir.

Çalışmada ayrıca şirketlerin lojistik faaliyetlerinde nesnelerin internetini benimserken karşılaşabilecekleri zorluklara da değinilmiştir. Lojistikte nesnlerin interneti kullanımı üzerine yapılan çalışmaların sistematik bir incelemesini sağlayan bu çalışma, nesnelerin interneti teknolojisinin lojistik faaliyetler üzerindeki etkisi ve şirketlerin nesnelerin interneti teknolojisini faaliyetlerine entegre ederken nelere dikkat etmesi gerektiği hakkında bir rehber niteliğinde olacak ve literatürdeki bu alandaki boşluğu nispeten dolduracak şekilde hazırlanmıştır.

Sonuç olarak nesnelerin interneti teknolojisi, lojistik faaliyetlerinde büyük bir potansiyele ve öneme sahiptir. Bu potansiyelin önümüzdeki yıllarda dikkatli bir şekilde ele alınarak ihtiyaçların giderilmesi lojistik sektöründe büyük gelişmeler sağlayacak ve alınacak yolda kullanılacak bu teknolojiler her aşamadan geçişi kolaylaştıracak bir araç özelliğini kazanacaktır.

\section{Kaynakça}

Aboubakar, M., Kellil, M., ve Roux, P. (2021). A review of IoT network management: Current status and perspectives. Journal of King Saud University - Computer and Information Sciences. doi:https://doi.org/10.1016/j.jksuci.2021.03.006
Agostino, Í. R. S., Ristow, C., Frazzon, E. M., ve Taboada Rodriguez, C. M. (2020, 2020//). Perspectives on the Application of Internet of Things in Logistics. Paper presented at the Dynamics in Logistics, Cham.

Akhter, R., ve Sofi, S. A. (2021). Precision agriculture using IoT data analytics and machine learning. Journal of King Saud University - Computer and Information Sciences. doi:https://doi.org/10.1016/j.jksuci.2021.05.013

Anitha, K., Palaksha Reddy, K., Krishnamoorthy, N., ve Jaiswal, S. (2021). IoT's in enabling the supply chain visibility and connectivity and optimization of performance. Materials Today:

Proceedings. doi:https://doi.org/10.1016/j.matpr.2020.12.343

Arif, J., el Farouk, I., Mouzouna, Y., ve Jawab, F. (2019). The use of internet of things (IoT) applications in the logistics outsourcing: Smart RFID tag as an example. Paper presented at the Proceedings of the International Conference on Industrial Engineering and Operations Management, Bangkok, Thailand.

Atzori, L., Iera, A., ve Morabito, G. (2010). The Internet of Things: A survey. Computer Networks, 54(15), 2787-2805. doi:https://doi.org/10.1016/j.comnet.2010.05.010

Babun, L., Denney, K., Celik, Z. B., McDaniel, P., ve Uluagac, A. S. (2021). A survey on IoT platforms: Communication, security, and privacy perspectives. Computer Networks, 192, 108040. doi:https://doi.org/10.1016/j.comnet.2021.108040

Brotsis, S., Limniotis, K., Bendiab, G., Kolokotronis, N., ve Shiaeles, S. (2021). On the suitability of blockchain platforms for IoT applications: Architectures, security, privacy, and performance. Computer Networks, 191, 108005. doi:https://doi.org/10.1016/j.comnet.2021.108005

Buntak, K., Kovačić, M., ve Mutavdžija, M. (2019). Internet of things and smart warehouses as the future of logistics. Tehnički glasnik, 13(3), 248-253.

Delgosha, M. S., Hajiheydari, N., ve Talafidaryani, M. (2021). Discovering IoT implications in business and management: A computational thematic analysis. Technovation, 102236. doi:https://doi.org/10.1016/j.technovation.2021.102236

Ding, Y., Jin, M., Li, S., ve Feng, D. (2021). Smart logistics based on the internet of things technology: an overview. International Journal of Logistics Research and Applications, 24(4), 323-345. doi:10.1080/13675567.2020.1757053

Farooq, M. S., Riaz, S., Abid, A., Abid, K., ve Naeem, M. A. (2019). A Survey on the Role of IoT in Agriculture for the Implementation of Smart Farming. IEEE Access, 7, 156237156271. doi:10.1109/ACCESS.2019.2949703

Firouzi, F., Farahani, B., ve Marinšek, A. (2021). The convergence and interplay of edge, fog, and cloud in the AIdriven Internet of Things (IoT). Information Systems, 101840. doi:https://doi.org/10.1016/j.is.2021.101840

Fizza, K., Banerjee, A., Mitra, K., Jayaraman, P. P., Ranjan, R., Patel, P., ve Georgakopoulos, D. (2021). QoE in IoT: a vision, survey and future directions. Discover Internet of Things, 1(1), 4. doi:10.1007/s43926-021-00006-7

Golpîra, H., Khan, S. A. R., ve Safaeipour, S. (2021). A review of logistics Internet-of-Things: Current trends and scope for future research. Journal of Industrial Information Integration, $\quad 22, \quad 100194$. doi:https://doi.org/10.1016/j.jii.2020.100194

Gulati, K., Kumar Boddu, R. S., Kapila, D., Bangare, S. L., Chandnani, N., ve Saravanan, G. (2021). A review paper on wireless sensor network techniques in Internet of Things 
(IoT). Materials Today: Proceedings. doi:https://doi.org/10.1016/j.matpr.2021.05.067

Hu, P., Ning, H., Qiu, T., Zhang, Y., ve Luo, X. (2017). Fog Computing Based Face Identification and Resolution Scheme in Internet of Things. IEEE Transactions on Industrial Informatics, 13(4), 1910-1920. doi:10.1109/TII.2016.2607178

Hussein, A. R. H. (2019). Internet of things (IOT): Research challenges and future applications. International Journal of Advanced Computer Science and Applications, 10(6), 77-82.

Ibarra-Esquer, J. E., González-Navarro, F. F., Flores-Rios, B. L., Burtseva, L., ve Astorga-Vargas, M. A. (2017). Tracking the Evolution of the Internet of Things Concept Across Different Application Domains. Sensors, 17(6), 1379.

Jagtap, S., Duong, L., Trollman, H., Bader, F., Garcia-Garcia, G., Skouteris, G., . . . Rahimifard, S. (2021). Chapter 5 - IoT technologies in the food supply chain. In C. M. Galanakis (Ed.), Food Technology Disruptions (ss. 175-211): Academic Press.

Kavre, M., Gadekar, A., ve Gadhade, Y. (2019, 18-20 Dec. 2019). Internet of Things (IoT): A Survey. Paper presented at the 2019 IEEE Pune Section International Conference (PuneCon).

Lawal, K., ve Rafsanjani, H. N. (2021). Trends, benefits, risks, and challenges of IoT implementation in residential and commercial buildings. Energy and Built Environment. doi:https://doi.org/10.1016/j.enbenv.2021.01.009

Lydekaityte, J., ve Tambo, T. (2020). Smart packaging: definitions, models and packaging as an intermediator between digital and physical product management. The International Review of Retail, Distribution and Consumer Research, 30(4), 377-410. doi:10.1080/09593969.2020.1724555

Macaulay, J., Buckalew, L., ve Chung, G. (2015). Internet of things in logistics. Retrieved from

Ouyang, Q., Zheng, J., ve Wang, S. (2019). Investigation of the construction of intelligent logistics system from traditional logistics model based on wireless network technology. EURASIP Journal on Wireless Communications and Networking, 2019(1), 20. doi:10.1186/s13638-018-1334-8

Rey, A., Panetti, E., Maglio, R., ve Ferretti, M. (2021). Determinants in adopting the Internet of Things in the transport and logistics industry. Journal of Business Research, 131, 584-590. doi:https://doi.org/10.1016/j.jbusres.2020.12.049

Ruile, H. (2021). How the Internet of Things Drives Innovation for the Logistics of the Future. In R. Dornberger (Ed.), New Trends in Business Information Systems and Technology: Digital Innovation and Digital Business Transformation (ss. 267-280). Cham: Springer International Publishing.

Sabireen, H., ve Venkataraman, N. (2021). A Review on Fog Computing: Architecture, Fog with IoT, Algorithms and Research Challenges. ICT Express, 7(2), 162-176. doi:https://doi.org/10.1016/j.icte.2021.05.004

Said, O., ve Tolba, A. (2021). Accurate performance prediction of IoT communication systems for smart cities: An efficient deep learning based solution. Sustainable Cities and Society, 69, 102830. doi:https://doi.org/10.1016/j.scs.2021.102830

Sergi, I., Montanaro, T., Benvenuto, F. L., ve Patrono, L. (2021). A Smart and Secure Logistics System Based on IoT and Cloud Technologies. Sensors, 21(6), 2231.

Shahid, N., ve Aneja, S. (2017, 10-11 Feb. 2017). Internet of Things: Vision, application areas and research challenges. aper presented at the 2017 International Conference on ISMAC (IoT in Social, Mobile, Analytics and Cloud) (ISMAC).

Singh, S. K., ve Roy, S. (2020). Internet of Things (IoT) Based Green Logistics Operations for Sustainable Development in the Indian Context, Singapore.

Song, Y., Yu, F. R., Zhou, L., Yang, X., ve He, Z. (2021). Applications of the Internet of Things (IoT) in Smart Logistics: A Comprehensive Survey. IEEE Internet of Things Journal, 8(6), 4250-4274. doi:10.1109/JIOT.2020.3034385

Statista. (2021). Number of Internet of Things (IoT) connected devices worldwide from 2019 to 2030, https://www.statista.com/statistics/1183457/iot-connecteddevices-worldwide/, (Erişim Tarihi: 13.07.2021)

Taliaferro, A., Ernst, R., Ahmed, U., Harolikar, A., ve Ray, S. (2019). Creating IoT ecosystems in transportation: Logistics companies are looking to connect IoT technologies to traditional systems. Retrieved from Toronto, Canada:

Thomas, M. O., ve Rad, B. B. (2017). Reliability evaluation metrics for internet of things, car tracking system: a review. Int. J. Inf. Technol. Comput. Sci.(IJITCS), 9(2), 1-10.

Tran-Dang, H., Krommenacker, N., Charpentier, P., ve Kim, D.S. (2020). The Internet of Things for Logistics: Perspectives, Application Review, and Challenges. IETE Technical Review, 1-29. doi:10.1080/02564602.2020.1827308

Tsogbaatar, E., Bhuyan, M. H., Taenaka, Y., Fall, D., Gonchigsumlaa, K., Elmroth, E., ve Kadobayashi, Y. (2021). DeL-IoT: A deep ensemble learning approach to uncover anomalies in IoT. Internet of Things, 14, 100391. doi:https://doi.org/10.1016/j.iot.2021.100391

van Geest, M., Tekinerdogan, B., ve Catal, C. (2021). Design of a reference architecture for developing smart warehouses in industry 4.0. Computers in Industry, 124, 103343. doi:https://doi.org/10.1016/j.compind.2020.103343

Verdouw, C. N., Robbemond, R. M., Verwaart, T., Wolfert, J., ve Beulens, A. J. M. (2018). A reference architecture for IoTbased logistic information systems in agri-food supply chains. Enterprise Information Systems, 12(7), 755-779. doi:10.1080/17517575.2015.1072643

Wang, J., Lim, M. K., Wang, C., ve Tseng, M.-L. (2021). The evolution of the Internet of Things (IoT) over the past 20 years. Computers \& Industrial Engineering, 155, 107174. doi:https://doi.org/10.1016/j.cie.2021.107174

$\mathrm{Yu}, \mathrm{W}$. (2019). Research on Optimization of Logistics Management Information System Based on Internet of Things. Paper presented at the 2019 5th International Conference on Education Technology, Management and Humanities Science (ETMHS 2019).

Zaychenko, I., Smirnova, A., Shytova, Y., Mutalieva, B., ve Pimenov, N. (2021). Digital Logistics Transformation: Implementing the Internet of Things (IoT), Cham.

Zhang, D., Liu, Y., Han, K., Liu, A., ve Liu, L. (2012). The Application of RFID-Based on IOT in Logistics Management, Berlin, Heidelberg.

Zhang, G., Shang, X., Alawneh, F., Yang, Y., ve Nishi, T. (2021). Integrated production planning and warehouse storage assignment problem: An IoT assisted case. International Journal of Production Economics, 234, 108058. doi:https://doi.org/10.1016/j.ijpe.2021.108058

Zhang, H., Zhang, G., ve Cai, X. (2021). Logistics Transfer Center Planning Based on Internet of Things Technology, Cham. 